\title{
Experimental Investigation of Dynamic Characteristics of Subsea Sand-Silt Mixtures
}

\author{
Tugen Feng, Yu Tang, Qiyenan Wang, Jian Zhang $\mathbb{D}^{D}$, and Jian Song $\mathbb{1}$ \\ Key Laboratory of Ministry of Education for Geomechanics and Embankment Engineering, Hohai University, \\ Nanjing 210098, China \\ Correspondence should be addressed to Jian Zhang; zhangj0507@163.com
}

Received 15 April 2019; Accepted 2 July 2019; Published 10 July 2019

Academic Editor: Castorina S. Vieira

Copyright (c) 2019 Tugen Feng et al. This is an open access article distributed under the Creative Commons Attribution License, which permits unrestricted use, distribution, and reproduction in any medium, provided the original work is properly cited.

In this paper, extensive resonant column tests were conducted to investigate dynamic responses of subsea sand-silt mixtures. The effects of confining pressure, mixture ratio, curing age, and cement content were evaluated. For the test condition considered in this study, the measured damping ratio is the smallest when the ratio of subsea sand to silt is in a range of 1.5 to 2.0. Moreover, unsolidified subsea sand-silt mixed at a ratio of 1.5 has almost the same maximum shear stiffness as the pure sand. For solidified subsea sand-silt mixture, cement can significantly increase the dynamic shear stiffness when the curing age is less than 14 days. However, the increase of the maximum dynamic shear stiffness is negligible when the curing age is longer than 14 days. When the cement content is $2 \%$, the damping ratio of the solidified mixtures is very close to that of the unsolidified mixture. When the cement content is higher than $4 \%$, the damping ratio of the solidified mixtures reduces significantly. This is mainly due to hydration reactions occurring in the solidified mixtures.

\section{Introduction}

Coastal levees are normally constructed to protect coastal areas, which are vulnerable to suffer the natural disasters such as typhoons and tsunamis. Construction of coastal levees requires a lot of fine-grain soils, but coastal areas lack these types of soils. The coastal levee studied in this paper is located in the coastal area of Fujian Province in China. A survey shows that there are tremendous amounts of subsea sands and silts. The subsea sand is coarse-grain soil which has high strength, low compressibility, and high permeability, while the silt is fine-grain soil which has low strength, high compressibility, and low permeability. Subsea sand is used mainly as a filler in highway engineering and in concrete materials for building engineering $[1,2]$. Solidification treatment, including the mixing of sea mud with a binding agent to create an improved material, represents a newly developed technology that is employed to reuse silt in China. The mechanical properties of silt and the treatmentimproved silt have been extensively analyzed [3-9], and modified silt has been used mainly as reinforcement soil for embankments [10], as high subgrade soil [11], and as backfilling soil at Haneda Airport [12]. At present, little research has been conducted to discuss the feasibility of employing subsea sand or silt as a filler for coastal levees considering their deficiencies. If the silt is mixed with subsea sand at an appropriate ratio, the mixture can have good engineering properties. Thus, the transformation of silt and subsea sand into a high-quality filler material is desirable both economically and practically.

Because coastal levees are vulnerable to suffer typhoons and tsunamis, to evaluate the safety and serviceability of coastal levees, dynamic responses of filler materials should be investigated. Many studies have been conducted to investigate the dynamic responses of sand and clay. Hardin and Black [13] and Seed and Idriss [14] proposed empirical equations for estimation of dynamic shear modulus and damping ratio of sand and clay, respectively. It is found that the dynamic shear modulus and damping ratio were significantly affected by soil type, shear strain, and effective confining pressure [15-25]. However, load frequency, vibration history, over consolidation ratio, and saturation had 
slight effects on the dynamic shear modulus and damping ratio [18, 26-29]. Recently, more and more studies were conducted to explore the dynamic characteristics of special soils. Kallioglou et al. [30] found that the organics had effects on the dynamic shear modulus and damping ratio of soil when the content of organics in soil was larger than $25 \%$. Tika et al. [31] found that cement additives had the ability to increase the dynamic shear modulus of soil in the small strain range but had little effect on damping ratio. Pantazopoulos and Atmatzidis [32] found that the water cement ratio had a great influence on the dynamic shear modulus of solidified sand. Senetakis et al. [33] found that the confining pressure and the grain-size characteristics hardly affected the rate of normalized modulus degradation and damping ratio of volcanic sands. Subramaniam and Banerjee [34] proposed that the degradation of shear modulus of solidified clay depended on various factors, such as number of loading cycles, cement content, curing days, cyclic shear strain, and loading frequency. $\mathrm{Li}$ et al. [35] explored the effects of confining pressure, mix proportion, and curing age on the dynamic shear modulus and damping ratio of steel slag sand mixture. In addition, many studies proposed various computational models to predict relationship among normalized dynamic shear stiffness $\left(G / G_{\max }\right)$, damping ratio $(D)$, and dynamic shear strain $(\gamma)$, such as the HardinDrnevich model [19], modified Hardin-Drnevich model [18], and Zhang model [36].

A mixture containing subsea sand and silt is a new type of artificial soil. As far as the authors are aware, limited studies have been conducted to investigate the dynamic responses of subsea sand-silt mixtures. In this study, the dynamic shear stiffness and damping ratio of subsea sandsilt mixtures were explored by extensive resonant column tests. The effects of confining pressure, mixture ratio, curing age, and cement content on the dynamic shear modulus and damping ratio of the mixtures were analyzed.

\section{Resonant Column Test}

2.1. Testing Apparatus. Figure 1 shows a photo of the GZZ50 resonance column testing apparatus used in this study. This apparatus is mainly used to investigate the dynamic shear stiffness $(G)$ and damping ratio $(D)$ of soil at a strain level of $10^{-6} \sim 2 \times 10^{-4}$. The testing apparatus mainly consisted of pressure chamber, static control system, vibration exciter control system, measurement system, industrial computer, test software, and accessories.

2.2. Testing Material and Sample Preparation. Because the experimental investigation in this paper is based on the project in Fuzhou, the subsea sand was taken from the sand yard in Jiangyin, Fuzhou, while the silt was taken from the sea entrance in Minjiang of the eastern Lang Qi Island, Fuzhou. Once the subsea sand and silt were collected, they were sealed with two layers of plastic bags to minimize the water evaporation. By conducting indoor geotechnical tests, the engineering properties of subsea sand and silt are summarized in Tables 1 and 2, respectively.

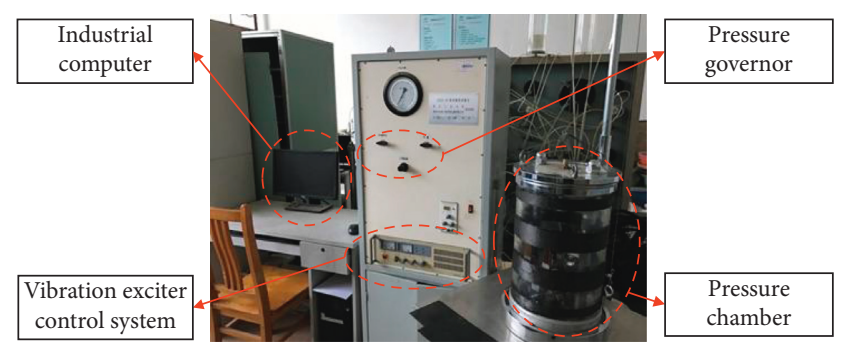

FIGURE 1: GZZ-50 resonance column testing apparatus.

Table 1: Properties of subsea sand.

\begin{tabular}{lccccc}
\hline $\begin{array}{l}\text { Natural } \\
\text { density, }\end{array}$ & $\begin{array}{c}\text { Specific } \\
\text { gravity, } \\
G_{\mathrm{s}}\end{array}$ & $\begin{array}{c}\text { Water } \\
\text { content } \\
w(\%)\end{array}$ & $\begin{array}{c}\text { Maximum } \\
\text { void ratio, } \\
e_{\max }\end{array}$ & $\begin{array}{c}\text { Minimum } \\
\text { void ratio, } \\
e_{\min }\end{array}$ & $\begin{array}{c}\text { Relative } \\
\text { density, } \\
D_{\mathrm{r}}\end{array}$ \\
\hline 2.57 & 2.66 & 62 & 0.76 & 0.52 & 0.35 \\
\hline
\end{tabular}

TABle 2: Properties of silt.

\begin{tabular}{lcccc}
\hline $\begin{array}{l}\text { Specific } \\
\text { gravity, } G_{\mathrm{s}}\end{array}$ & $\begin{array}{c}\text { Rate of water } \\
\text { content } w(\%)\end{array}$ & $\begin{array}{c}\text { Liquid } \\
\text { limit } \\
w_{\mathrm{L}}(\%)\end{array}$ & $\begin{array}{c}\text { Plastic limit } \\
w_{\mathrm{p}}(\%)\end{array}$ & $\begin{array}{c}\text { Plastic } \\
\text { index } I_{\mathrm{P}}\end{array}$ \\
\hline 2.74 & 63.0 & 40.6 & 23.6 & 17 \\
\hline
\end{tabular}

Figure 2 shows the particle size distribution curves of subsea sand and silt. The nonuniformity coefficients $\left(C_{\mathrm{u}}\right)$ and curvature coefficients $\left(C_{c}\right)$ of these two kinds of soils are shown in Table 3. Note that $d_{60}$ means the percentage of particles with $d \leq 60 \mathrm{~mm}, d_{30}$ means the percentage of particles with $d \leq 30 \mathrm{~mm}$, and $d_{10}$ means the percentage of particles with $d \leq 10 \mathrm{~mm}$. Based on the basic properties of subsea sand and silt, the subsea sand was classified as wellgraded sand while the silt was classified as a clay with low liquid limit.

2.3. Testing Program and Procedures. In this paper, the dynamic shear stiffness $(G)$ and damping ratio $(D)$ of subsea sand-silt mixtures at different ratios were obtained by conducting resonance column tests. The effects of mixture ratio, consolidation confining pressure, cement content, and curing age on dynamic shear modulus and damping ratio of soil samples were analyzed. All the soil samples were consolidated isotopically, and they were tested under the confining pressures of $100 \mathrm{kPa}, 200 \mathrm{kPa}, 300 \mathrm{kPa}$, and $400 \mathrm{kPa}$, respectively.

The subsea sand was first sieved (i.e., controlled diameter was $2 \mathrm{~mm}$ ). Then, the subsea sand is mixed with silt at ratios (i.e., the ratio of the mass of subsea sand to the mass of silt) of $2: 1,1.5: 1,1: 1,1: 1.5$, and $1: 2$. A summary of resonant column tests of unsolidified mixtures is shown in Table 4 . For the solidified mixtures, the preparation method of soil samples was the same as the unsolidified mixtures. The conventional R32.5 Portland cement was used to solidify the subsea sand-silt mixtures. The cement contents (i.e., cement weight to soil weight) designed in this study were $2 \%, 4 \%$, $6 \%, 8 \%$, and $10 \%$, respectively. 


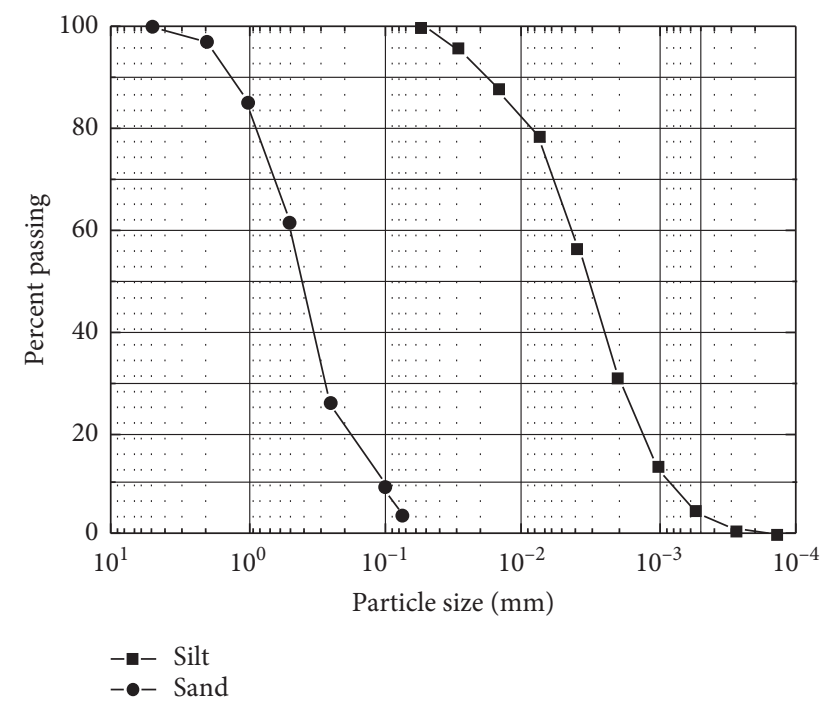

FIgURE 2: Particle size distribution curves of subsea sand and silt.

TABLE 3: Nonuniformity coefficients and curvature coefficients of subsea sand and silt.

\begin{tabular}{lccccc}
\hline Soilsamples & $d_{60}(\mathrm{~mm})$ & $d_{30}(\mathrm{~mm})$ & $d_{10}(\mathrm{~mm})$ & $\begin{array}{c}C_{\mathrm{u}}=d_{60} / \\
d_{10}\end{array}$ & $\begin{array}{c}C_{\mathrm{c}}=d_{30}^{2} / \\
\left(d_{10} \cdot d_{60}\right)\end{array}$ \\
\hline $\begin{array}{l}\text { Subsea } \\
\text { sand }\end{array}$ & 0.49 & 0.26 & 0.096 & 5.1 & 1.4 \\
Silt & 0.0048 & 0.0019 & 0.0008 & 6.0 & 0.94 \\
\hline
\end{tabular}

TABLE 4: Dry density and water content of the mixtures.

\begin{tabular}{lccccccc}
\hline $\begin{array}{l}\text { Ratio of } \\
\text { sand/Silt }\end{array}$ & $\begin{array}{c}\text { Subsea } \\
\text { sand }\end{array}$ & $2: 1$ & $1.5: 1$ & $1: 1$ & $1: 1.5$ & $1: 2$ & Silt \\
\hline $\begin{array}{l}\text { Controlling } \\
\text { dry density } \\
\text { (g/cm }{ }^{3} \text { ) }\end{array}$ & 1.59 & 1.38 & 1.34 & 1.28 & 1.22 & 1.18 & 0.98 \\
$\begin{array}{l}\text { Water } \\
\text { content (\%) }\end{array}$ & 6.2 & 12.3 & 16.0 & 20.2 & 26.9 & 32.1 & 63.0 \\
\hline
\end{tabular}

To minimize friction between soil and the chamber, a layer of Vaseline was applied on the inner wall. The inner diameter and height of the chamber were $50 \mathrm{~mm}$ and $100 \mathrm{~mm}$, respectively. Based on the designed soil density, each soil sample was prepared by five layers to ensure the uniformity. After compaction, the surface of the last layer of soil was ensured to be smooth. Each sample was placed in a sealed box filled with wet sand for 24 hours. For the solidified mixtures, they were kept in a clear water tank.

The vacuum machine was used to saturate each soil sample. Each soil sample was placed in the vacuum chamber for at least 2 hours. Then, de-aired water was added in the vacuum chamber and each soil sample was submerged underneath the water for at least 10 hours. For solidified mixtures, soil samples were kept in the de-aired water for 7 days, 14 days, and 28 days (i.e., curing age), respectively.

\section{Dynamic Responses of Unsolidified Mixtures}

3.1. Dynamic Shear Stiffness of Unsolidified Mixtures.
Because dynamic responses of mixtures at each controlled confining pressure are similar, only dynamic shear stiffness and damping ratio under the confining pressure of $100 \mathrm{kPa}$ are presented in this section.

Figure 3 shows the variation of measured dynamic shear stiffness $(G)$ with shear strain $(\gamma)$ under the confining pressure of $100 \mathrm{kPa}$. When the dynamic shear strain is less than $2 \times 10^{-3} \%$, the shear stiffness is almost independent of shear strain. At this strain range, responses of soil can be classified as elastic behaviors and the corresponding shear stiffness can be considered as the maximum dynamic shear stiffness. When the shear strain is larger than $2 \times 10^{-3} \%$, an increase in the dynamic shear strain results in a significant reduction of dynamic shear stiffness. When the ratio of subsea sand to silt is less than 1.5, the dynamic shear stiffness increases significantly with the increasing ratio. By further increasing the ratio, the increase of dynamic shear stiffness is negligible.

Figure 4 shows the relationship between the maximum dynamic shear modulus $\left(G_{\max }\right)$ and ratio of mixtures at various confining pressures. As expected, the maximum dynamic shear stiffness increases rapidly as an increase in the confining pressure. At a given confining pressure, the maximum dynamic shear stiffness increases with the mixture ratio of subsea sand to silt but at a reduced rate. When the value of the ratio is smaller than 1.5 , by adding the silt in the sand, the silt can reduce the soil stiffness and permeability simultaneously. When the value of the ratio is larger than 1.5, the maximum shear stiffness of soil samples at the mixed ratio of 1.5 is almost the same (i.e., 90 97\%) as that of pure sand. For this condition, the stiffness of mixtures is not reduced by adding silt, but the permeability of mixtures may be significantly decreased. Obviously, a larger shear stiffness of soil corresponds to a smaller soil deformation. In terms of dynamic shear stiffness and soil deformation, the optimal mixture ratio of subsea sand and silt is thus suggested to be 1.5.

From the discussion about Figures 3 and 4, it can be deduced that when the value of the ratio is smaller than 1.5 , by adding the sand into the silt, the $G$ and $G_{\max }$ values of the mixtures increase because the shear stiffness of sand is larger than that of silt. However, when the value of the ratio is larger than 1.5 , the soil skeleton is mainly formed by the sand (small particles of silt fill the pores among the particles of sand), and the mixtures show no significant change with the increase of sand content.

In this study, the adopted testing apparatus can only capture the dynamic soil responses at a strain level of $10^{-4} \sim 2 \times 10^{-2} \%$. The dynamic responses of soil at large strains need to be predicted by empirical equations. Based on numerous tests, Hardin and Drnevich [19] proposed that the $G-\gamma$ curve is hyperbolic type, and Hardin and Drnevich proposed a Hardin-Drnevich model to reveal the relationship between $G$ and $\gamma$. Compared with other empirical equations (e.g., Davidenkov model), the Hardin-Drnevich model has advantages of less parameters, simple calculation, definite physical meaning, and so on. However, the fitting results of the Hardin-Drnevich model are weak. To improve the fitting precision of the Hardin-Drnevich model, 


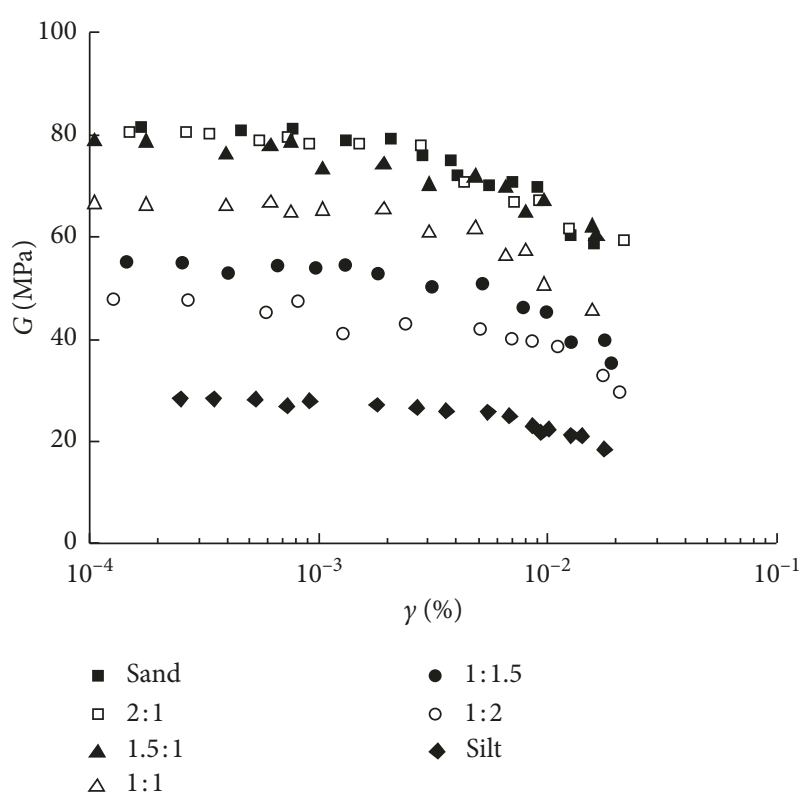

FIGURE 3: Variation of measured $G$ with $\gamma$ under the confining pressure of $100 \mathrm{kPa}$.

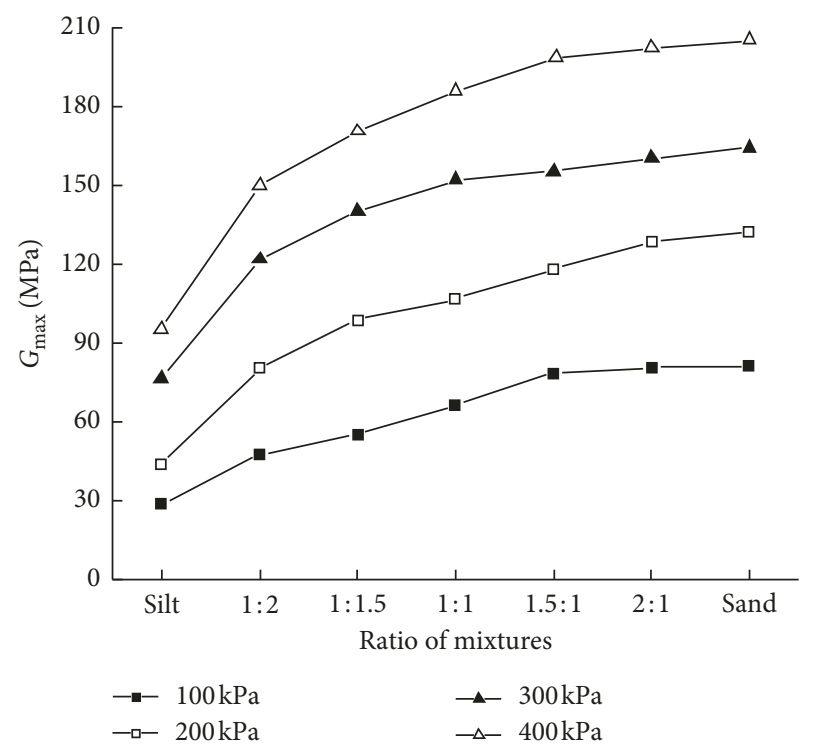

FIgURE 4: Variation of $G_{\max }$ with ratio of mixtures at various confining pressures.

Darendeli [18] added a new parameter (curvature coefficient), and a modified Hardin-Drnevich model was presented. In this paper, a modified Hardin-Drnevich model is used to fit the $G / G_{\max }-\gamma$ curve. The formula of this modified model is expressed by

$$
\frac{G}{G_{\max }}=\frac{1}{1+\left(\gamma / \gamma_{\mathrm{r}}\right)^{n}}
$$

where $\gamma_{\mathrm{r}}$ is the reference shear strain and it is the shear strain at $G / G_{\max }=0.5$ and $n$ is the curvature coefficient, which can be obtained through fitting the measure dynamic shear modulus.
By using the modified Hardin-Drnevich model to fit the measured dynamic shear stiffness at small and medium strains, the dynamic shear stiffness at large strains can be deduced. Since stiffness degradation curves $\left(G / G_{\max }-\gamma\right.$ curves) under different confining pressures are similar, only the stiffness degradation curve under the confining pressure of $100 \mathrm{kPa}$ is presented in Figure 5. When the confining pressure ranges from 200 to $400 \mathrm{kPa}$, similar observation of the stiffness degradation curve is obtained. The normalized dynamic shear stiffness $\left(G / G_{\max }\right)$ is the smallest for the pure silt. When the mixture ratio is less than 1.5 , a gradual increase in the normalized dynamic shear stiffness $\left(G / G_{\max }\right)$ is observed as the mixture ratio of soil is increased. When the ratio of mixtures is larger than $1.5, G / G_{\max }$ decreases with the increasing mixture ratio. Figure 5 also shows that for the confining pressures considered in this study, dynamic shear stiffness of subsea sand-silt mixtures at different ratios can be reasonably captured by the empirical equation proposed by Seed and Idriss [37].

3.2. Damping Ratio of Unsolidified Mixtures. Figure 6 shows the variation of measured damping ratio $(D)$ of subsea sandsilt mixtures at small and medium strains under the confining pressure of $100 \mathrm{kPa}$. Based on the measured damping ratio at small-medium strains, the damping ratio at large strains is deduced using empirical equations by fitting measured damping ratios at small and medium strains. Although the model proposed by Hardin and Drnevich [19] is simple, the damping value is equal to 0 when $G=G_{\max }$, and the fitting results are weak. Later, based on numerous tests, Zhang et al. [36] proposed the Zhang model (a polynomial function). This model is simple and can provide good fitting results. Thus, the Zhang model is used to fit the $D-\gamma$ curve. This model is expressed by

$$
D-D_{\min }=k_{1}\left(\frac{G}{G_{\max }}\right)^{2}+k_{2}\left(\frac{G}{G_{\max }}\right)+k_{3} \text {, }
$$

where $D_{\text {min }}$ is the minimum damping ratio, and it can be obtained at $\gamma=10^{-6} ; k_{1}, k_{2}$, and $k_{3}$ can be obtained by fitting the measured damping ratio.

Figure 7 shows the variation of fitted damping ratio with shear strain at different mixture ratios. For the confining pressure of $100 \mathrm{kPa}$, the relationship between the damping ratio and shear strain can be reasonably estimated by the empirical equations proposed by Seed and Idriss [37]. When the ratio of mixtures is less than 2 , an increase in the subsea sand can cause a reduction in the damping ratio. When soil sample is purely made of silt, the damping ratio is the largest. This is because the stiffness of silt is small, and it can cause large reduction of energy when wave is propagated in the pure silt. Through adding sand into silt, the stiffness of subsea sand-silt mixture can be improved because the sand has much higher stiffness than the silt. When wave is propagated in these mixtures, energy loss is small and the damping ratio is smaller than that of pure silt. However, the damping ratio of pure sand is much larger than that of subsea sand-silt mixtures at a ratio of 2 . This is because pure subsea sand has high porosity (for mixtures, the silt can fill 


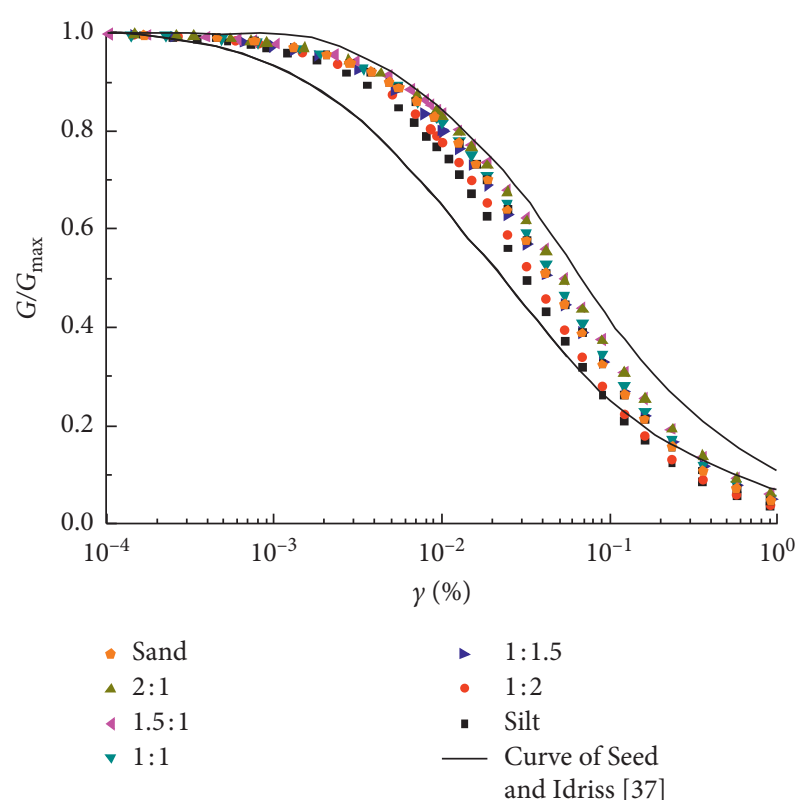

Figure 5: Variation of fitted $G / G_{\max }$ with $\gamma$ under the confining pressure of $100 \mathrm{kPa}$.

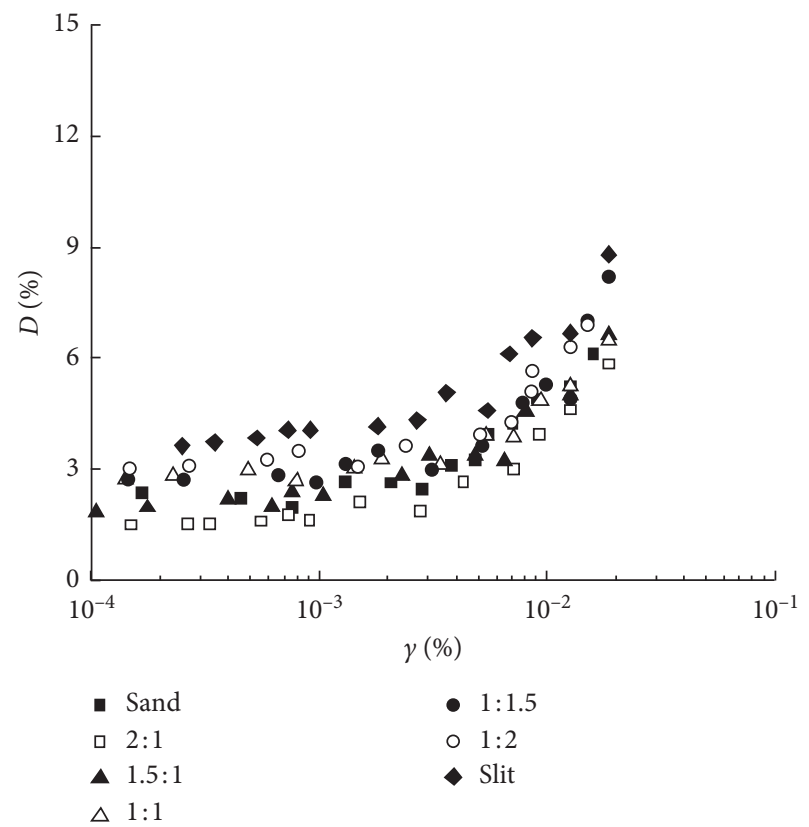

FIgURE 6: Variation of $D$ with $\gamma$ at small and medium strains under the confining pressure of $100 \mathrm{kPa}$.

the gap among sand particles) and small contact area between soil particles. When wave is propagated in the pure sand, the velocity of wave propagation becomes slow and energy loss is large.

3.3. Discussion. When silt is mixed with subsea sand, small particles of silt fill the pores among the particles of subsea sand. For cases that the ratio of subsea sand to silt is less than 1.5 , with an increase in the proportion of silt, the damping ratio is improved and the dynamic shear stiffness and

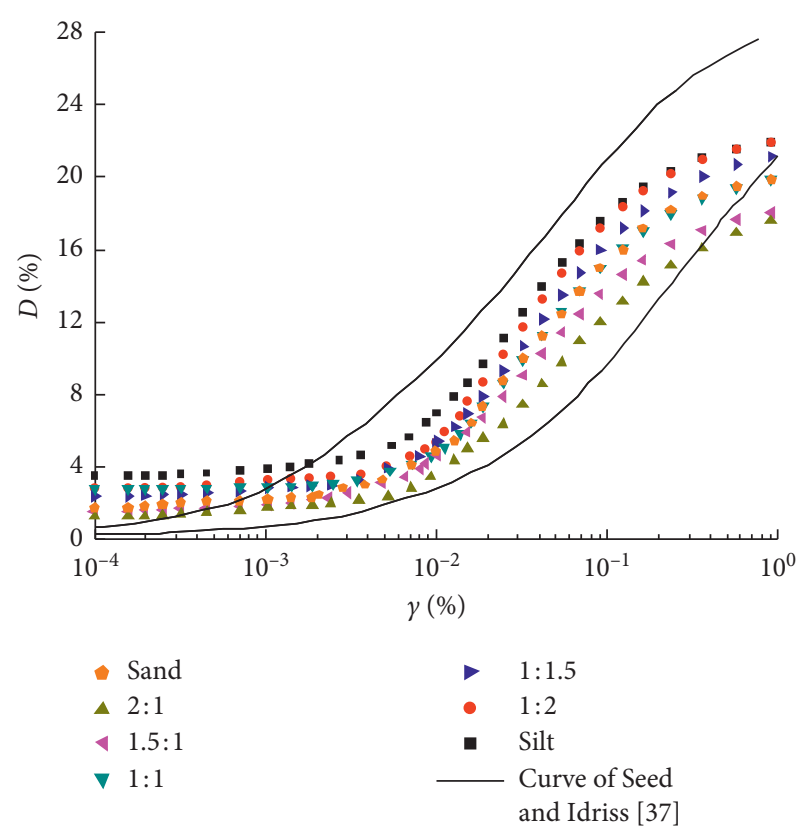

Figure 7: Variation of fitted $D$ with $\gamma$ under the confining pressure of $100 \mathrm{kPa}$.

maximum dynamic shear modulus have little change under the confining pressure of $100 \mathrm{kPa}$. However, when the content of silt continues to increase, superfluous particles of silt cannot fill the porosity of subsea sand. The dynamic shear stiffness, maximum dynamic shear modulus, and the damping ratio begin to decrease due to silt's poor geotechnical properties. For all the tests conducted in this study, the shear stiffness is almost the same as the pure sand when the subsea sand-silt mixture ratio is equal to 1.5 . At this mixture ratio, the damping ratio is also small. It is demonstrated that again subsea sand-silt at a mixture ratio of 1.5 is a reasonable choice. Because coastal levees are vulnerable to suffer typhoons and tsunamis, dynamic loads, such as earthquake or wave actions, should be considered. At this time, higher quality subsea sand-silt mixtures are needed. In order to improve the strength and stiffness of filling materials, cement is added to solidify the mixture.

\section{Dynamic Responses of Solidified Mixtures}

4.1. Dynamic Shear Stiffness of Solidified Mixtures. Based on the dynamic response of unsolidified mixture, the subsea sand-silt mixed at a ratio of 1.5 gives good engineering properties. Thus, the ratio of subsea-sand to silt of solidified mixtures is selected as 1.5 . Because variations of dynamic shear stiffness of solidified mixtures at different curing ages and confining pressures are similar, only the measured dynamic shear stiffness at curing age of 7 days and confining pressure of $100 \mathrm{kPa}$ is presented in Figure 8 . As shown in the figure, the variation of the dynamic shear stiffness with shear strain is similar with the unsolidified mixture. As expected, the dynamic shear stiffness of solidified mixtures increases with an increase in the cement content $N_{\mathrm{c}}$ (i.e., $N_{\mathrm{c}}$ increases from $2 \%$ to $10 \%$ ). 


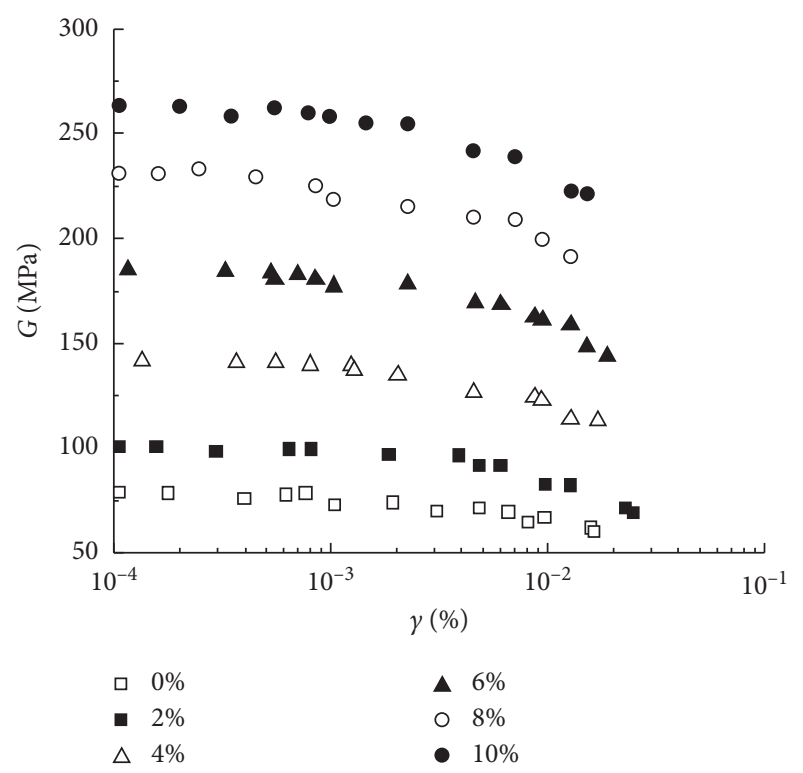

FIGURE 8: Variation of measured $G$ with $\gamma$ of solidified mixtures at curing age of 7 days and confining pressure of $100 \mathrm{kPa}$.

In order to evaluate the solidification effects, the maximum dynamic shear stiffness of solidified mixtures is compared with the unsolidified mixtures. Herein, growth rate of the maximum dynamic stiffness $G_{\mathrm{G}}$ is defined by the following equation:

$$
G_{\mathrm{G}}=\frac{G_{\mathrm{max}, \text { solidified }}-G_{\text {max,unsolidified }}}{G_{\max , \text { unsolidified }}} .
$$

Figure 9 shows the growth rate of the maximum dynamic stiffness $\left(G_{\mathrm{G}}\right)$ at different curing ages $(7,14$, and 28 days) and cement contents $(2 \%$ and $10 \%)$. When the curing age is increased from 7 to 28 days, the maximum shear dynamic stiffness is increased but at a reduced rate. When the curing age is less than 14 days, cement can significantly increase the maximum dynamic shear stiffness, especially for soil consolidated at high confining pressures. However, the increase of the maximum dynamic shear stiffness is negligible when the curing age is longer than 14 days. It implies that the appropriate curing age is 14 days. The increase of dynamic shear stiffness is due to hydration reaction. In the early curing age, the speed of hydration reaction is fast, resulting in a significant increase in the dynamic shear stiffness. All the growth rates of the maximum dynamic stiffness at different confining pressures and cement contents are summarized in Table 5.

Based on the dynamic shear stiffness of solidified mixtures at small and medium shear strains, the shear stiffness at large strains can be deduced from the Hardin-Drnevich model. Figure 10 shows the variation of the normalized dynamic shear stiffness $\left(G / G_{\max }\right)$ with the shear strain. The confining pressure is $100 \mathrm{kPa}$, and the curing age is 7 days. When $N_{c}=2 \%$, the normalized shear stiffness versus shear strain curve is almost the same as that of unsolidified mixture. It implies that a low cement content has limited effects on dynamic responses of solidified mixtures. If the

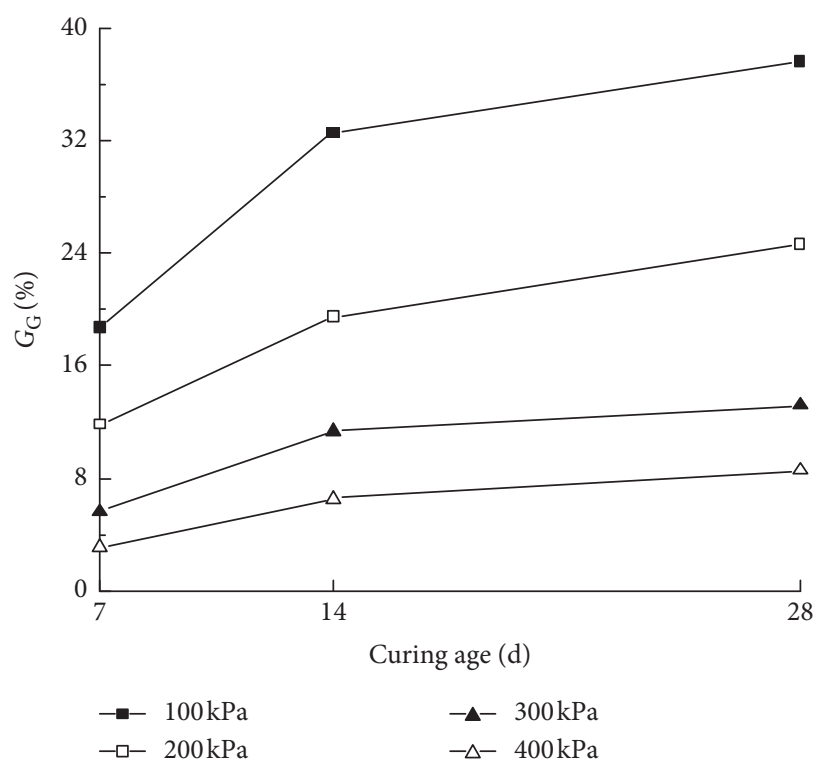

(a)

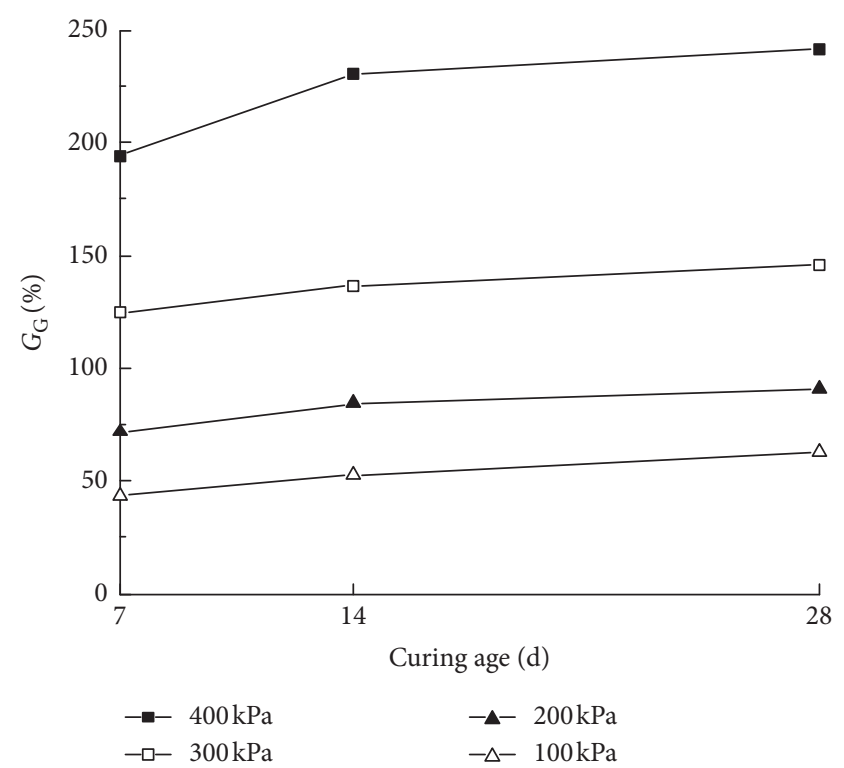

(b)

FIgURE 9: Variation of $G_{G}$ with curing age of solidified mixtures. (a) $N_{\mathrm{c}}=2 \%$. (b) $N_{\mathrm{c}}=10 \%$.

value of $N_{c}$ is higher than $6 \%$, the normalized shear stiffness at a given shear strain is much larger than that of unsolidified mixtures. This is because when the cement content is high, much large amount of hydration reaction occurs in solidified mixtures, resulting in hardening of solidified mixtures.

4.2. Damping Ratio of Solidified Mixtures. Figure 11 shows the measured damping ratio $(D)$ of solidified mixtures at different cement contents within the medium and small strain range. As shown in the figure, a large cement content gives a small damping ratio.

Based on the measured damping ratio at small and medium strains, the damping ratio of solidified mixtures is 
TABLE 5: Growth rate of $G_{\max }$ of solidified mixtures.

\begin{tabular}{lcccccc}
\hline $\begin{array}{c}\text { Curing } \\
\text { age }(\mathrm{d})\end{array}$ & $\begin{array}{c}\text { Confining } \\
\text { pressure }(\mathrm{kPa})\end{array}$ & $2 \%$ & $4 \%$ & $6 \%$ & $8 \%$ & $10 \%$ \\
\hline \multirow{4}{*}{7} & 100 & 18.75 & 56.25 & 106.25 & 157.75 & 193.75 \\
& 200 & 11.86 & 35.59 & 65.25 & 100.85 & 124.58 \\
& 300 & 5.66 & 20.75 & 37.11 & 57.23 & 71.70 \\
& 400 & 3.03 & 11.61 & 23.73 & 36.36 & 43.43 \\
\hline \multirow{4}{*}{14} & 100 & 32.50 & 82.50 & 132.48 & 190.23 & 230.17 \\
& 200 & 19.49 & 53.39 & 85.59 & 116.10 & 136.44 \\
& 300 & 11.32 & 26.42 & 48.43 & 70.44 & 84.28 \\
& 400 & 6.57 & 16.67 & 31.31 & 45.45 & 52.52 \\
\hline \multirow{4}{*}{28} & 100 & 37.50 & 96.25 & 151.25 & 202.75 & 241.25 \\
& 200 & 24.58 & 61.02 & 94.49 & 128.81 & 145.76 \\
& 300 & 13.21 & 37.74 & 62.26 & 81.76 & 91.12 \\
& 400 & 8.58 & 21.71 & 42.93 & 54.55 & 62.63 \\
\hline
\end{tabular}

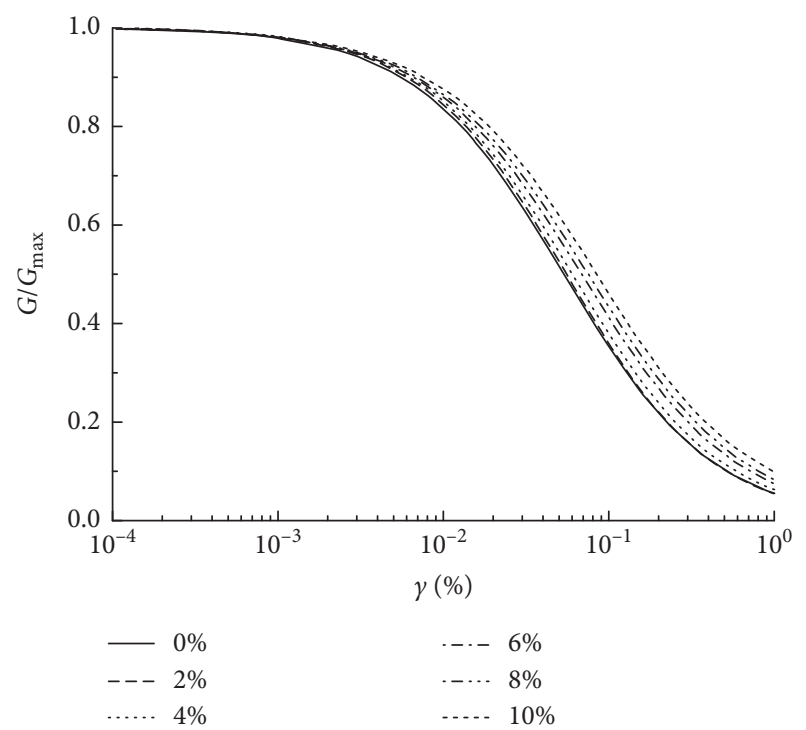

FIGURE 10: Variation of fitted $G / G_{\max }$ with $\gamma$ of solidified mixtures at curing age of 7 days and confining pressure of $100 \mathrm{kPa}$.

deduced from the Zhang model. As shown in Figure 12, the fitted damping ratio of each sample is similar when the shear strain is less than $10^{-3} \%$. With an increase in the shear strain, the difference of damping ratio of mixtures at different cement contents becomes more obvious. When $N_{\mathrm{c}}=2 \%$, the damping ratio of the solidified mixtures is very close to that of the unsolidified mixtures. If the value of $N_{\mathrm{c}}$ is higher than $4 \%$, the damping ratio of the solidified mixtures reduces significantly. This is because after hydration reactions, the hydration products (e.g., calcium silicate hydrate, hydrated calcium aluminate, and calcium hydroxide) are formed, and sand particles can be bonded together causing a reduction in the void ratio of solidified mixtures. It means that a large cement content corresponds to a stiff soil. When wave is propagated in a stiff soil, energy loss is small, giving a small damping ratio.

4.3. Discussion. Microstructural studies of solidified mixtures show that their mechanical behavior is governed primarily by hydrates. Hydrates are the reaction products

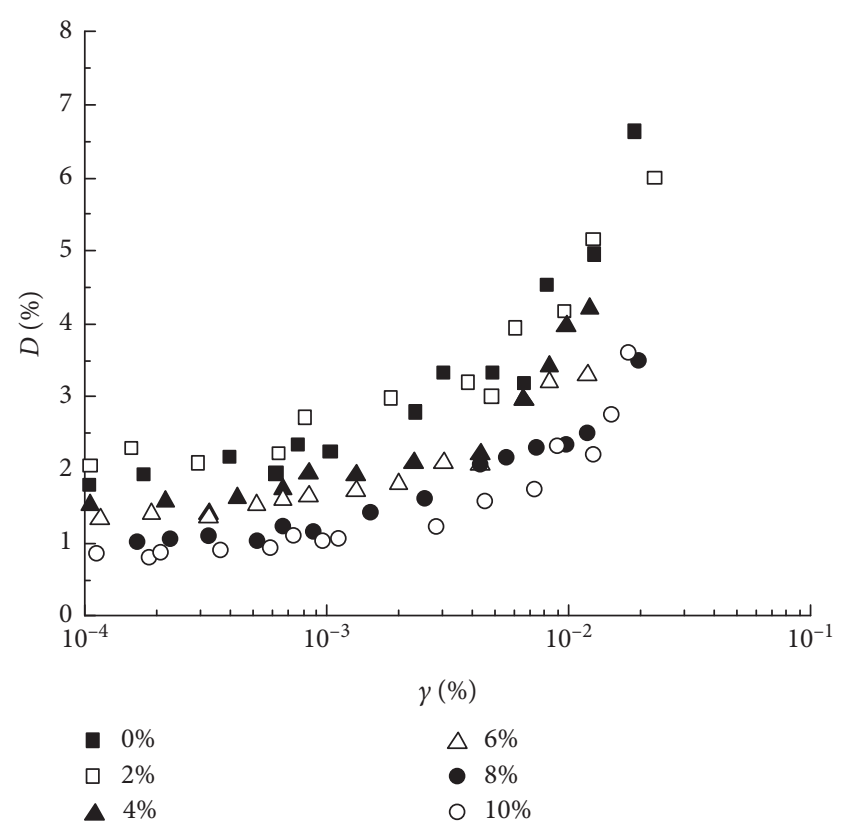

Figure 11: Variation of measured $D$ with $\gamma$ of solidified mixtures at curing age of 7 days and confining pressure of $100 \mathrm{kPa}$.

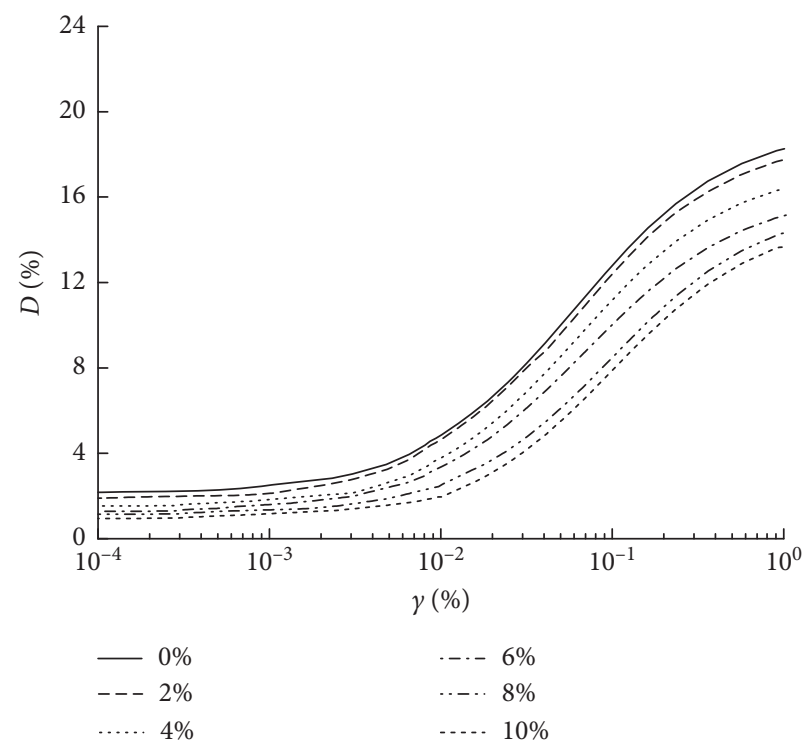

FIgURE 12: Variation of fitted $D$ with $\gamma$ of solidified mixtures at curing age of 7 days and confining pressure of $100 \mathrm{kPa}$.

among a binding agent, minerals in the soil, and water. After hydration reactions, the hydration products (e.g., calcium silicate hydrate, hydrated calcium aluminate, and calcium hydroxide) are formed. On the one hand, these products can fill the pores among the mixture particles and produce a network structure that is stronger than the original soil skeleton. On the other hand, through ion exchange and pelletization, aggregates possessing good compactness are formed. Those gels and aggregates can bind particles together and generate a strong chain structure. Therefore, the dynamic shear stiffness, maximum dynamic shear modulus, and the damping ratio of the 
mixture can be improved by mixing it with cement. Note that a low cement content has limited effects on dynamic responses of solidified mixtures, and a large cement content corresponds to a stiff soil.

\section{Conclusions}

In this paper, extensive resonant column tests were conducted to investigate dynamic response of subsea sand-silt mixture. The effects of confining pressure, mixture ratio, curing age, and cement content were evaluated. Based on the measured results, the following conclusions may be drawn:

(1) As the ratio of subsea sand to silt is increased, the dynamic shear stiffness of unsolidified soils increases significantly when the ratio is less than 1.5. By further increasing the subsea sand-silt ratio, the increase of dynamic shear stiffness is negligible. For the test condition considered in this study, unsolidified subsea sand-silt mixed at a ratio of 1.5 has almost the same maximum shear stiffness as the pure sand.

(2) Since there are many pores in pure sand, the damping ratio of sand is much larger than unsolidified subsea sand-silt mixture. By adding the silt to fill the pores among sand particles, the damping ratio of subsea sand-silt mixtures is decreased. When the ratio of subsea sand to silt is in a range of 1.5 to 2.0, the measured damping ratio is the smallest. In terms of shear stiffness and damping ratio, the optimal ratio of subsea sand to silt is suggested to be 1.5.

(3) For solidified subsea sand-silt mixture, cement can significantly increase the maximum dynamic shear stiffness when the curing age is less than 14 days. However, the increase of the maximum dynamic shear stiffness is negligible when the curing age is longer than 14 days. It implies that the appropriate curing age is 14 days.

(4) When the cement content is $2 \%$, the damping ratio of the solidified mixtures is very close to that of the nonsolidified mixture. If the cement content is higher than $4 \%$, the damping ratio of the solidified mixtures reduces significantly. This is mainly due to a series of hydration reactions occurring in the solidified mixture.

\section{Data Availability}

The data used to support the findings of this study are available from the corresponding author upon request.

\section{Conflicts of Interest}

There are no conflicts of interest regarding the publication of this paper.

\section{Acknowledgments}

This work was sponsored by the Fundamental Research Funds for the Central Universities (nos. 2019B44114 and
2018B57014) and the National Natural Science Foundation of China (no. 51808193). The authors are grateful for this support.

\section{References}

[1] K. Siham, B. Fabrice, A. N. Edine, and D. Patrick, "Marine dredged sediments as new materials resource for road construction," Waste Management, vol. 28, no. 5, pp. 919-928, 2008.

[2] R. Zentar, V. Dubois, and N. E. Abriak, "Mechanical behaviour and environmental impacts of a test road built with marine dredged sediments," Resources Conservation and Recycling, vol. 52, no. 6, pp. 947-954, 2008.

[3] A. J. Quiroga, Z. M. Thompson, K. K. Muraleetharan, G. A. Miller, and A. B. Cerato, "Stress-strain behavior of cement-improved clays: testing and modeling," Acta Geotechnica, vol. 12, no. 5, pp. 1003-1020, 2017.

[4] X. Bian, Y.-J. Cui, L.-L. Zeng, and X.-Z. Li, "Swelling behavior of compacted bentonite with the presence of rock fracture," Engineering Geology, vol. 254, pp. 25-33, 2019.

[5] X. Bian, Y.-J. Cui, and X.-Z. Li, "Voids effect on the swelling behaviour of compacted bentonite," Géotechnique, vol. 69, no. 7, pp. 593-605, 2019.

[6] P. Liu, S. Wang, L. Ge, M. Thewes, J. Yang, and Y. Xia, "Changes of Atterberg limits and electrochemical behaviors of clays with dispersants as conditioning agents for EPB shield tunnelling," Tunnelling and Underground Space Technology, vol. 73, pp. 244-251, 2018.

[7] J. Song, Q. Fan, T. Feng, Z. Chen, J. Chen, and Y. Gao, “A multi-block sliding approach to calculate the permanent seismic displacement of slopes," Engineering Geology, vol. 255, pp. 48-58, 2019.

[8] S. Wang, R. Luna, and S. Onyejekwe, "Postliquefaction behavior of low-plasticity silt at various degrees of reconsolidation," Soil Dynamics and Earthquake Engineering, vol. 75, pp. 259-264, 2015.

[9] J. Zhang, T. G. Feng, F. H. Zhang, and W. B. Li, "Experimental study on improvement of seawall filler materials composed of sea sand and sea mud," Marine Georesources and Geotechnology, pp. 1-11, 2019.

[10] T. K. Ogino, T. G. Kataoka, and K. Kuroda, "Utilization of stabilized dredged waste for construction material," in Proceedings of the First International Congress on Environmental Geotechnics, pp. 49-56, Canadian Geotechnical Society, Edmonton, Alberta, Canada, July 1994.

[11] Y. H. Huang, W. Zhu, C. L. Zhang, S. C. Wang, and N. Zhang, "Experimental study on dredged material improvement for highway subgrade soil: paving materials and pavement analysis," in Proceedings of the American Society of Civil Engineers GeoShanghai International Conference 2010, vol. 203, pp. 335-340, Shanghai, China, June 2010.

[12] K. Morohoshi, K. Yoshinaga, M. Miyata et al., "Design and long-term monitoring of tokyo international airport extension project constructed on super-soft ground," Geotechnical and Geological Engineering, vol. 28, no. 3, pp. 223-232, 2010.

[13] B. O. Hardin and W. L. Black, "Vibration modulus of normally consolidated clay," Journal of the Soil Mechanics and Foundations Division, vol. 94, no. 2, pp. 353-370, 1968.

[14] H. B. Seed and I. M. Idriss, "A simplified procedure for evaluating soil liquefaction potential," Journal of Soil Mechanics and Foundations Division, vol. 97, no. 9, pp. 12491273, 1971. 
[15] B. Amir-Faryar, M. S. Aggour, and R. H. Mccuen, "Universal model forms for predicting the shear modulus and material damping of soils," Geomechanics and Geoengineering, vol. 12, no. 1, pp. 60-71, 2017.

[16] A. Anastasiadis, K. Pitilakis, K. Senetakis, and A. Souli, "Dynamic response of sandy and gravelly soils: effect of grain size characteristics on $G-\gamma-D$ curves," in Proceedings of the 5 th International Conference on Earthquake Geotechnical Engineering, Santiago, Chile, January 2011.

[17] R. Chattaraj and A. Sengupta, "Liquefaction potential and strain dependent dynamic properties of Kasai River sand," Soil Dynamics and Earthquake Engineering, vol. 90, pp. 467-475, 2016.

[18] M. B. Darendeli, Development of a New Family of Normalized Modulus Reduction and Material Damping Curves, The University of Texas at Austin, Austin, TX, USA, 2001.

[19] B. O. Hardin and V. P. Drnevich, "Shear modulus and damping in soils: design equation and curves," Journal of the Soil Mechanics and Foundations Division, vol. 98, no. 7, pp. 667-692, 1972.

[20] T. Iwasaki and F. Tatsuoka, "Effects of grain size and grading on dynamic shear moduli of sands," Soils and Foundations, vol. 17, no. 3, pp. 19-35, 1977.

[21] T. Kokusho, "Cyclic triaxial test of dynamic soil properties for wide strain range," Soils and Foundations, vol. 20, no. 2, pp. 45-60, 1980.

[22] K. H. Stokoe, M. B. Darendeli, R. D. Andrus, and L. T. Brown, "Dynamic soil properties: laboratory, field and correlation studies," in Proceedings of the Second International Conference on Earthquake Geotechnical Engineering, Sêco e Pinto, Ed., pp. 811-845, Rotterdam, Balkema, Lisbon, Portugal, June 1999.

[23] K. H. Stokoe II., S. K. Hwang, J. N. K. Lee, and R. D. Andrus, "Effects of various parameters on the stiffness and damping of soils at small to medium strains," in Proceedings, International Symposium on Prefailure Deformation Characteristics of Geomaterials, vol. 2, pp. 785-816, Japanese Society of Soil Mechanics and Foundation Engineering, Sapporo, Japan, September 1994.

[24] V. C. Xenaki and G. A. Athanasopoulos, "Dynamic properties and liquefaction resistance of two soil materials in an earthfill dam-laboratory test results," Soil Dynamics and Earthquake Engineering, vol. 28, no. 8, pp. 605-620, 2008.

[25] S. Yniesta and S. J. Brandenberg, "Stress-ratio-based interpretation of modulus reduction and damping curves," Journal of Geotechnical and Geoenvironmental Engineering, vol. 143, no. 1, article 06016021, 2017.

[26] A. C. Cherian and J. Kumar, "Effects of vibration cycles on shear modulus and damping of sand using resonant column tests," Journal of Geotechnical and Geoenvironmental Engineering, vol. 142, no. 12, article 06016015, 2016.

[27] X. S. Li and W. L. Yang, "Effects of vibration history on modulus and damping of dry sand," Journal of Geotechnical and Geoenvironmental Engineering, vol. 124, no. 11, pp. 1071-1081, 1998.

[28] K. H. Stokoe II. and J. C. Santamarina, "Seismic-wave-based testing in geotechnical engineering, keynote paper," in Proceedings of the International Conference on Geotechnical and Geological Engineering, GeoEng 2000, Melbourne, Australia, November, 2000.

[29] J. Sun, M. Gong, and X. Tao, "Dynamic shear modulus of undisturbed soil under different consolidation ratios and its effects on surface ground motion," Earthquake Engineering and Engineering Vibration, vol. 12, no. 4, pp. 561-568, 2013.
[30] P. Kallioglou, T. Tika, G. Koninis, S. Papadopoulos, and K. Pitilakis, "Shear modulus and damping ratio of organic soils," Geotechnical and Geological Engineering, vol. 27, no. 2, pp. 217-235, 2009.

[31] T. Tika, P. Kallioglou, G. Koninis, P. Michaelidis, M. Efthimiou, and K. Pitilakis, "Dynamic properties of cemented soils from Cyprus," Bulletin of Engineering Geology and the Environment, vol. 69, no. 2, pp. 295-307, 2010.

[32] I. A. Pantazopoulos and D. K. Atmatzidis, "Dynamic properties of microfine cement grouted sands," Soil Dynamics and Earthquake Engineering, vol. 42, pp. 17-31, 2012.

[33] K. Senetakis, A. Anastasiadis, and K. Pitilakis, "Normalized shear modulus reduction and damping ratio curves of quartz sand and rhyolitic crushed rock," Soils and Foundations, vol. 53, no. 6, pp. 879-893, 2013.

[34] P. Subramaniam and S. Banerjee, "Factors affecting shear modulus degradation of cement treated clay," Soil Dynamics and Earthquake Engineering, vol. 65, no. 65, pp. 181-188, 2014.

[35] W. Li, L. Lang, D. Wang, Y. Wu, and F. Li, "Investigation on the dynamic shear modulus and damping ratio of steel slag sand mixtures," Construction and Building Materials, vol. 162, pp. 170-180, 2018.

[36] J. Zhang, R. D. Andrus, and C. H. Juang, "Normalized shear modulus and material damping ratio relationships," Journal of Geotechnical and Geoenvironmental Engineering, vol. 131, no. 4, pp. 453-464, 2005.

[37] H. B. Seed and I. M. Idriss, "Soil moduli and damping factors for dynamic response analysis," EERC Report No. 70-10, Earthquake Engineering Research Center, University of California, Berkeley, CA, USA, 1970. 


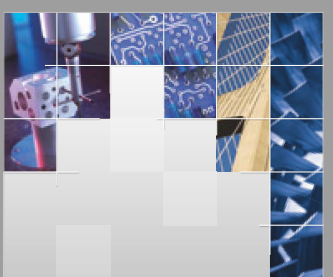

\section{Enfincering}
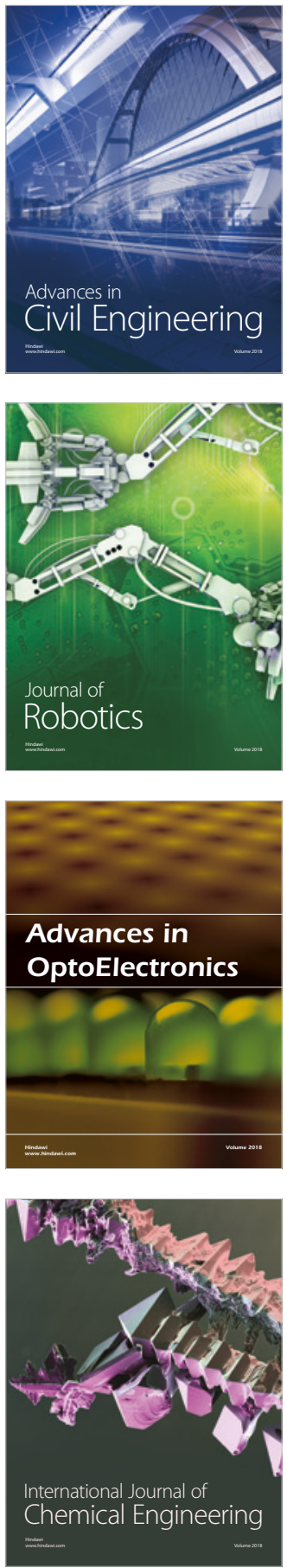

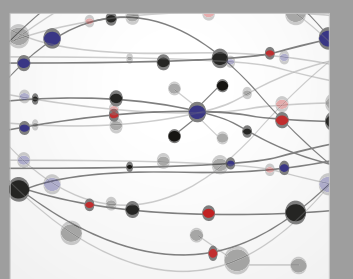

\section{Rotating \\ Machinery}

The Scientific World Journal

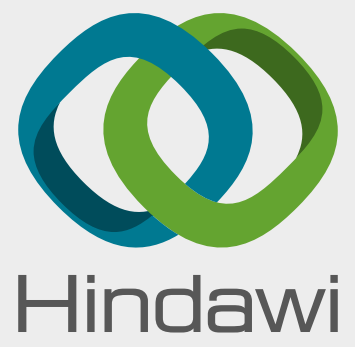

Submit your manuscripts at

www.hindawi.com
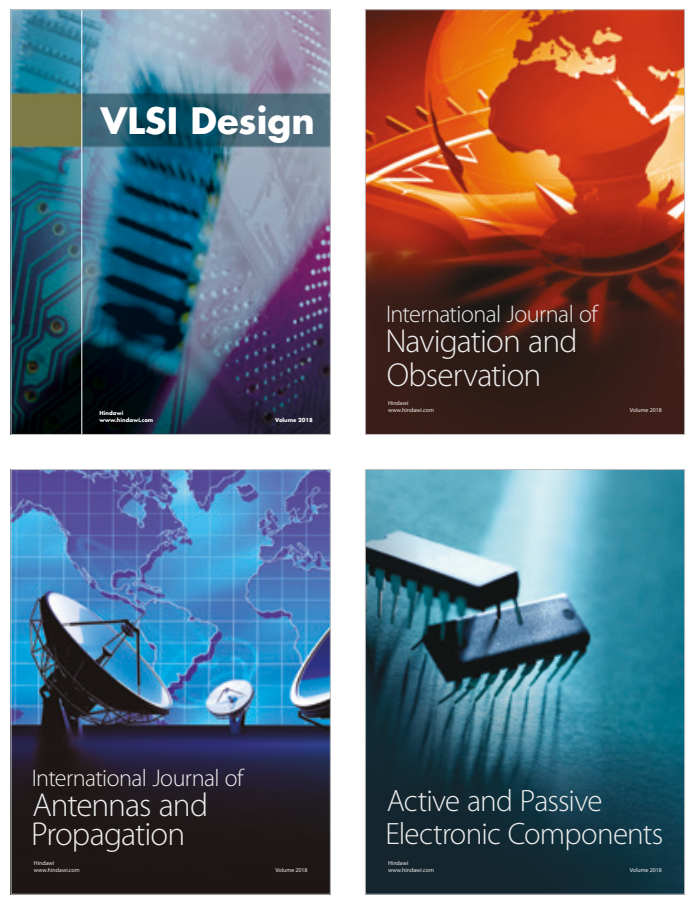
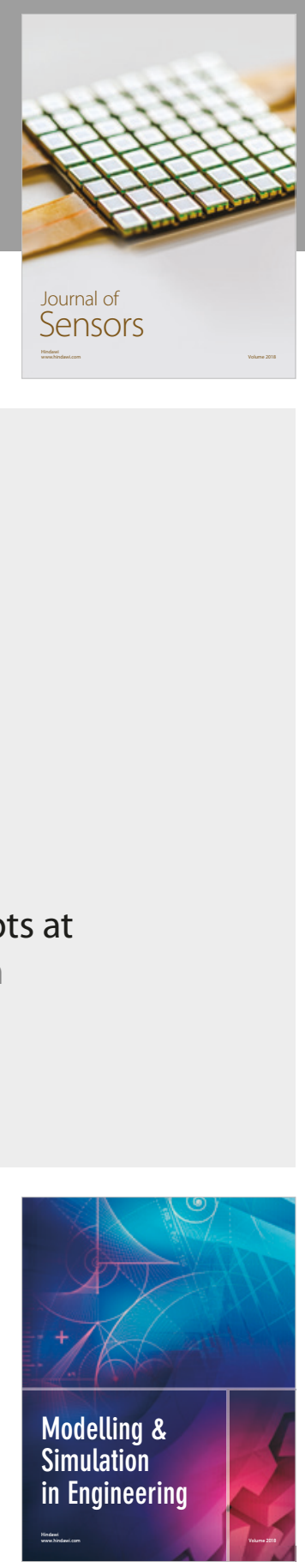

\section{Advances \\ Multimedia}
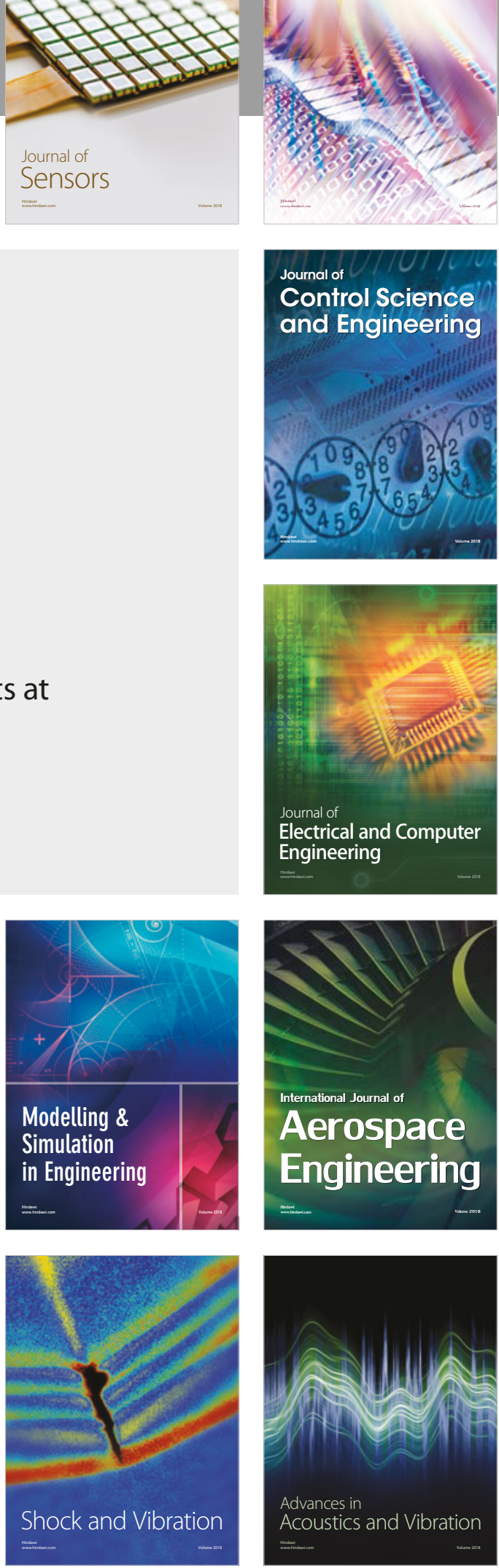